\title{
La propiedad de la tierra como fuente del poder local. Santa Fe entre el voto censitario y el sufragio universal
}

\author{
MANUEL MARTINEZ MARTIN \\ DAVID MARTINEZ LOPEZ \\ SALVADOR CRUZ ARTACHO
}

\section{INTRODUCCION}

Con el presente trabajo pretendemoś aproximarnos a la articulación de la estructura política y socioeconómica del municipio de Santa Fé a lo largo del período de la Restauración. Una somera descripción del proceso de las transformaciones agrarias liberales, configuradoras de una estructura de la propiedad perfilada completamente a mediados de siglo $\mathrm{XIX}$, y un estudio de la organización del poder político local y de sus conexiones con los aparatos de control político provinciales nos proporcionaran un marco analítico suficiente donde valorar la incidencia de la implantación del, sufragio electoral masculino sobre el tejido social y político de la comunidad santafesina.

En este sentido proponemos un estudio de la estructura de la propiedad que refleje el proceso de expansión y consolidación de la burguesía agraria local así como una visión de las estructura política local en tres momentos diferentes -1856, 1887 y 1891- que nos permitan conocer el entramado de fuerzas políticas y económicas hegemónicas y si aquél sufre algún tipo de modificación a consecuencia de la ley electoral implantada por Sagasta en 1890 durante el segundo gobierno liberal(1885-1890)1.

En lo que respecta a las fuentes utilizadas, el aparato principal se basa en documentos de tipo fiscal -Amillaramiento de 1856 y Repartimientos de la Contribución Territorial y Pecuaria de los años 1887 y 1892- que, a pesar de posibles distorsicnes a la baja en la estimación de los líquidos imponibles, ofrecen información suficiente para el cstudio de

(1) Sole Tura, J. y' Aja, E. Constituciones y periodos constituyentes en España (1808-1936). Madrid: Siglo XX, 1984. pp. 75-78.

DOI: http://dx.doi.org/10.25267/Trocadero.1993.i5.13 
la propiedad y la distribución de las rentas líquidas por dicho concepto. Para determinar la composición de los órganos de gobierno municipal recurrimos a las Actas de Cabildo del Ayuntamiento de Santa Fé de los años $1856,1887,1892$ y $1893^{2}$. La consulta de numerosos legajos sobre herencias, dotes, particiones, compra-venta y arrendamientos, localizados en los Protocolos Notariales ${ }^{3}$, nos facilitó la reconstrucción de las .familias* que constituyen la oligarquía económica y política santafesina y que proporciona una visión más generosa del poder en Santa Fé.

Finalmente, el rastreo a través de varios años del principal organismo de prensa granadino, *El Defensor de Granada*, y del *Boletín Oficial de la Provincia de Granadan nos ha proporcionado informaciones complementarias para el seguimiento de los distintos procesos electorales.

\section{LA PROPIEDAD DE LA TIERRA COMO BASE DEL CONTROL DEL PODER LOCAL A COMIENZOS DE LA SEGUNDA MITAD DEL XIX.}

\subsection{La consolidación de la burguesía agraria en Santa Fe.}

La estructura de la propiedad agraria en Santa Fe, en 1856, presentaba modificaciones sustanciales respecto a situaciones anteriores, como consecuencia del desarrollo del capitalismo agrario en la Vega de Granada. La distribución de la propiedad se caracteriza por su desequilibrio, es decir, concentración/dispersión, reflejada en un reducido número de propietarios que concentran la mayor parte de la superficie y un numeroso grupo de pequeños propietarios que controlan una reducida extensión del término municipal, característica ésta muy común al resto de las comunidades campesinas andaluzas ${ }^{4}$. Esta coexistencia entre la pequeña y la gran propiedad, junto a un numerosísimo grupo de campesinos sin tierra, que ya existía a mediados del XVIII', no se ve alterada sino reforzada en sus extremos como consecuencia de los cambios liberales agrarios hacia la segunda mitad del XIX.

(2) Amillaramientos, Repartimientos de la Contribución territorial y pecuaria, y las Actas del Cabildo han sido localizados en el Archivo Municipal de Santa Fé.

(3) Esta documentación se encuentra en el Archivo de Protocolos Notariales de Granada. La relación de los legajos utilizados comprende las fechas entre 1840 y 1892 . En adelante nos referiremos a esta fuente como -Archivo de Protocolos Notariales de Granada.

(4) Gonzalez de Molina, M. y Sevilla Guzmán, E. •Minifundio y gran propiedad agraria: estabilidad y cambio en la Alta Andalucía. 1750-1930., en Jornadas de Historia Agraria. Santiago de Compostela, Diciembre de 1988 (en prensa).

(5) Martínez Martín, M. sequeña y gran explotación en la Vega de Ganada, una dualidad constante. Santa Fe entre 1752 y 1916. En II Congreso de Historia de Andalucia. Córdoba, abril de 1991. 
El proceso desamortizador había puesto en manos de unas pocas familias, propietarias y arrendatarias, tanto los bienes de la iglesia como los bienes municipales ${ }^{6}$. Este proceso tiene como consecuencia, en primer lugar, un aumento del número de propietarios, sobre todo los más pequeños, pero al mismo tiempo concentra aún más la propiedad, con lo que disminuye la extensión media de las pequeñas propiedades. También ocurre que el número de familias que tienen acceso a la propiedad, se redujera respecto a 1752 a pesar del aumento de los propietarios, dado el ritmo de crecimiento de la población, llegando a duplicar los habitantes durante la segunda mitad del XVIII y la primera del XIX.

En principio este resultado parece confirmar las tesis clásicas del desarrollo del capitalismo ${ }^{7}$, caracterizadas a grandes rasgos, por la progresiva concentración de la propiedad acompañada por un aumento de la proletarización de los pequeños campesinos. Esto supone que la comunidad se encuentra en un avanzado estado de proletarización donde el capitalismo ha logrado descomponer la homogeneidad del campesinado tradicional, considerando a éste como la avanzadilla del campesinado que debe proletarizarse. Este esquema creemos que es válido en lo que se refiere al estudio de la propiedad, puesto que si tomamos otras variables de análisis se modifica significativamente el modelo descrito.

El aumento del número de propietarios y de la superficie agrícola significa un proceso de campesinización derivado de las medidas agrarias liberales (Desamortización y Desvinculación), así como de la propia dinámica del mercado de tierras, aunque relativamente suponga un menor acceso a la propiedad por parte de los grupos domésticos campesinos y por tanto contribuya a acentuar el marcado carácter proletario de buena parte de los efectivos poblacionales de la comunidad.

En segundo lugar, si cambiamos la fuente analítica de la propiedad por la explotación, esta situación cambia de manera sustancial. De este modo el acceso campesino al cultivo de la tierra, a través de formulas alternativas a la propiedad como el arrendamiento, aumenta de manera considerable. Esto se observa claramente en la tabla I.

El recurso al arrendamiento hace que el número de familias que acceden al cultivo de la tierra llegue casi a duplicarse provocando un fenómeno de campesinización aunque fuese a costa de la reducción del tamaño medio de la explotación. Los cambios agrarios liberales han empujado hacia la tierra determinando un fenómeno de concentración y a la vez de dispersión de la propiedad y la explotación.

(6) Gómez Oliver, M. y Gonzalez de Molina, M. .Transferencias de propiedad y Desamortización. El caso de Santa Fe (1760-1894). Ayuntamiento de Santa Fe. Santa Fe, 1983.

(7) Lenin, V. El desarrollo del Capitalismo en Rusia. Barcelona. Ed. Laia; 1974. 
Tabla I.

Distribución de la propiedad y la explotación de los vecinos en 1856.

\begin{tabular}{rcccr} 
& \multicolumn{2}{c}{ Propiedad } & \multicolumn{2}{c}{ Explotación } \\
Has. & No Prop. & Extens. & $N^{2}$ Expl. & Extens. \\
$0-1$ & 76 & 35 & 155 & 78 \\
$1-5$ & 41 & 90 & 101 & 217 \\
$5-10$ & 9 & 65 & 13 & 89 \\
$10-50$ & 26 & 599 & 32 & 820 \\
$50-100$ & 6 & 438 & 10 & 701 \\
+100 & 0 & 0 & 2 & 272 \\
Total & 158 & 1228 & 313 & 2176
\end{tabular}

Fuente: Amillaramiento de 1856 y Padrón de vecinos de 1855 (A. M. Santa Fe).

De esta forma el cultivador directo, despojado de bienes y usos comunales, encuentra en el arrendamiento una vía de subsistencia, al mismo tiempo que queda a merced de la voluntad de los propietarios y grandes arrendatarios que han accedido a la propiedad. Esta situación de dependencia económica provoca una nueva dependencia, en esta caso política ${ }^{8}$, sobre todo a nivel local, que hace que el campesino pierda su posible representatividad en los órganos de gobierno municipales, al mismo tiempo que la oligarquía local, es decir, las cuatro familias que componen la burguesía agraria, complete el circulo de dominación política, económica y social. De este modo el campesinado, que ocupa un lugar de subordinación en la esfera de las relaciones de producción, equipara su situación política a su situación económica, de dependencia a la clase dominante, como así lo demuestra la distribución y composición del poder local a mediados del XIX.

\subsection{La distribución del producto líquido agrario en 1887}

A la altura de 1887 la burguesía agraria santafesina estaba plenamente consolidada aconómica y políticamente. El proceso de concentración de tierra en su poder, iniciado con las transformaciones agrarias liberales, no se había detenido. Este proceso se vio continuado gracias a la introducción y desarrollo de la remolacha azucarera como cultivo fundamental y a la

(8) Un interesante análisis de las relaciones entre comportamientos políticos y estructura socioeconómica es efectuado por James SCOTT «Patronazgo y explotación. en Ernest GELLNER (et alii) Patronos y clientes. Barcelona: Júcar, 1977. Pags. 63-77. 
industria del azúcar, suponiendo un incremento de la actividad económica en la Vega Granadina, durante el último tercio del XIX, de tal envergadura que ha sido denominado como irevolucionario ‘. Esta dinamización de la vida económica, en torno al azúcar, favoreció la intensificáción y el desarrollo de las relaciones de producción capitalistas de producción. Al mismo tiempo sirvió para que la burguesía agraria santafesina incrementara su dominio sobre la tierra y consolidara su acceso a los organismos de poder local y provincial permitiéndoles garantizar el mantenimiento y reproducción de las relaciones sociales vigentes.

Según el repartimiento individual para satisfacer la contribución territorial, urbana y pecuaria del año económico de 1887 existen en Santa Fe 1020 contribuyentes de los cuales 860 son vecinos de la comunidad. Si tenemos en cuenta que la población debe rondar los 6000 habitantes tenemos que existen unos 1450 grupos domésticos. Según esta cifra hay 590 cabezas de familia, es decir un $41 \%$ que no posee absolutamente nada: Esta visión desequilibrada se acentúa aún más si nos ceñimos exclusivamente a la actividad agraria y pecuaria, puesto que la contribución urbana, a pesar de que su propiedad supone una inversión productiva, solo es una fuente de ingresos para unos pocos puesto que la mayoría de sus propietarios la utilizan como vivienda familiar. Centrándonos en la actividad agraria tenemos la existencia de 556 titulares de contribución rústica, tanto en propiedad como en colonia. Las cuotas forasteras ascienden a 149 , suponen el $26.7 \%$ y controlan algo más del $28 \%$ del líquido imponible.

\section{Tabla II}

Distribución del producto líquido por rústica y colonia entre los vecinos de Santa Fé en 1887.

$\begin{array}{rrrrr}\text { Pts } & \text { No Contri } & \% & \text { P. Líquido } & \% \\ 0-100 & 277 & 68.06 & 10026.24 & 7.02 \\ 100-250 & 51 & 12.53 & 8015.24 & 5.61 \\ 250-500 & 28 & 6.88 & 9840.76 & 6.89 \\ 500-1000 & 25 & 6.14 & 18021.71 & 12.62 \\ 1000-2500 & 11 & 2.70 & 17942.69 & 12.57 \\ 2500-5000 & 10 & 2.46 & 36907.28 & 25.85 \\ +5000 & 5 & 1.23 & 41996.98 & 29.42 \\ \text { Total } & 407 & 100.00 & 142750.90 & 100.00\end{array}$

Fuente: Repartimiento de la contribución territorial, urbana y pecuaria para el año económico 1887 a 1888 (A.M. Santa Fe).

(9) Martín Rodríguez, M. Azícar y descolonización. Granada: Universidad de Granada, 1982. Pags. $171-178$ y 234-237. 
La tabla II contiene los líquidos de los vecinos de Santa Fe. Los rangos de distribución que hemos establecido, responden a los utilizados recientemente por Carmen Frias Corredor ${ }^{10}$ para definir ínfima, pequeña, mediana y gran propiedad. Dicha tesis utiliza rangos referidos a cuotas impositivas, nosotros recogemos dentro de los mismos el producto líquido.

Dos características a resaltar: primero, el aumento de las explotaciones en conjunto respecto a 1856, pasando de 439 a 556. En segundo lugar, el mayor incremento se da en las que poseen los vecinos de Santa Fe y dentro de éstas el aumento se registra en las de menores dimensiones, definidas como ínfimas. Por tanto se ha agudizado el acceso al cultivo directo de forma más generalizada, al mismo tiempo que vuelve a reducirse el tamaño medio de las explotaciones. La introducción de la remolacha azucarera ha tenido mucho que ver con estos cambios. También aumentan en número las pequeñas, mientras que las medianas, consideradas entre 250 y 1000 pts de líquido imponible reducen su presencia y sobre todo su producto líquido. En último lugar, tenemos a las grandes propiedades y explotaciones que aunque manteniéndose en número, aumentan de manera considerable el líquido imponible. De nuevo los rasgos existentes en 1856, concentración/dispersión aparecen acentuados y consolidados.

Esta agudización de la distribución de la propiedad y de las explotaciones, ya existente, hace aumentar la dependencia de los campesinos respecto a la burguesía agraria propietaria. La alta rentabilidad de la remolacha azucarera hace subir los arrendamientos, permitiendo a los propietarios extraer una mayor plusvalía relativa al controlar mayor superficie en propiedad. Este auge, que beneficia tanto a cultivadores directos como a los propietarios, así como a los fabricantes de azúcar, pronto se ve truncado por una primera crisis en el sector azucarero. Dicha crisis tiene consecuencias importantes para los pequeños campesinos, muchos de ellos deben abandonar la explotación de la tierra y engrosar en las filas proletarias.

\subsection{Incidencia de la primera crisis de la remolacha azucarera: $1887-18^{\circ} 2$}

Según Manuel Martín Rodriguez ${ }^{11}$, tras una serie de buenas cosechas que alcanzan el punto de máxima rentabilidad, tanto para fabricantes como para agricultores, hacia 1888 se produce un período de crisis. Esta

(10) Frías Cc.rredor, C. Liberalismo y republicanismo en el Alto Aragón. Procesos electorales y compont..nientos politicos 1875-1898. Tesis doctoral. Universidad de Zaragoza, 1991. Pags. 331-333.

(11) Martín Rodriguez, M. Azuicar.... Op. cit. 
crisis, coyuntural, viene provocada por la degeneración de la semilla de la remolacha, bajando sus índices sacarinos de manera importante y obligando a aumentar costes de producción a los fabricantes de azúcar, reduciendo finalmente los precios de compra. Esto hace que la rentabilidad de su producción se vea seriamente afectada, provocando la caída de su cultivo. Este proceso acaba hacia 1892 cuando una mejor selección de las semillas y un mayor esmero en el proceso productivo de la remolacha hace que su rentabilidad alcance los valores obtenidos en 1888; pero sus efectos se dejan notar muy rápidamente en la estructura productiva como demuestra la tabla III.

Queda reflejado como esta situación de crisis no va a pasar desapercibida: La situación creada no afecta a todos los cultivadores directos y propietarios por igual, sino que son las pequeñas propiedades y explotaciones las que se ven más seriamente dañadas. Son 57 las explotaciones que desaparecen del primer rango, consideradas como ínfimas, cuya precariedad económica ha hecho que no aguanten un corto período de bajos precios, mostrándose mucho más vulnerables a la crisis. Es la introducción de este nuevo cultivo, cuya racionalidad económica es muy distinta a la que mantenían los cultivos tradicionales que venían desarrollando los campesinos, mucho menos monetarizados y menos dependientes del mercado, el que hace mucho más vulnerable la resistencia campesina a las situaciones de crisis. Las pequeñas y medianas se mantienen en niveles parecidos a 1887. Son las de mayores dimensiones las que vuelven a concentrarse ( +1000 rs de producto líquido). Por tanto la crisis ha provocado la ruina de pequeños propietarios y la proletarización de muchos de los cultivadores directos en régimen de arrendamiento, dada sus escasas posibilidades monetarias y su debilidad económica para resistir las adversas condiciones. Así el desarrollo de la actividad económica ha contribuido a aumentar las diferencias que existían entre los grandes propietarios y la gran mayoría campesina. De esta forma el desarrollo del capitalismo alimenta las diferencias de clase pero al mismo tiempo proporciona el control del poder a la burguesía, como clase dominante e impide la propia lucha política, primero con mecanismos jurídicos que dejan fuera del juego a la mayoría de la población que no posee cierto nivel de rentas y en segundo lugar, una vez abolidos estos mecanismos y liberalizado el juego político, a través de la dependencia económica total respecto a los que poseen los medios de producción.

En conjunto, entre 1887 y 1892 se da un aumento de la desigualdad entre las clases sociales. Esta progresiva concentración de la riqueza y aumento del deterioro de las condiciones de vida de las clases más desfavorecidas, que ven como cada vèz se hace más difícil su propia reproducción y la de sus familias, contribuye al aumento de los antago- 
nismo de clase. Esto es más comprensible cuando estamos en un período de crisis finisecular generalizado que hace perder capacidad adquisitiva a la mayor parte de la población perceptora de escasas rentas ${ }^{12}$.

\section{Tabla III}

Distribución del producto líquido por rústica y colonia entre los vecinos de Santa Fe en 1892.

$\begin{array}{ccccc}\text { Pts } & \text { N } \text { Nontri }^{2} & \% & \text { P. Líquido } & \% \\ 0-100 & 220 & 60.44 & 7891.23 & 5.47 \\ 100-250 & 54 & 14.84 & 8583.34 & 5.89 \\ 250-500 & 39 & 10.71 & 14299.48 & 9.81 \\ 500-1000 & 17 & 4.67 & 11798.80 & 8.09 \\ 1000-2500 & 22 & 6.04 & 34895.29 & 23.93 \\ 2500-5000 & 5 & 1.37 & 16893.20 & 11.58 \\ +5000 & 7 & 1.92 & 51372.46 & 35.23 \\ \text { Total } & 364 & 100.00 & 145823.80 & 100.00\end{array}$

Fuente: Repartimiento de la contribución territorial, urbana y pecuaria para el año económico 1892 a 1893 (A.M. Santa Fe).

\section{LA ESTRUCTURA DEL PODER LOCAL ANTES DE LA INSTAURACION DEL SUFRAGIO UNIVERSAL MASCULINO}

Hemos puesto de manifiesto cómo la concentración de la propiedad, consecuencia directa de la desamortización, ha provocado una mayor pérdida de la homogeneidad de la comunidad campesina y por tanto ha contribuido a un aumento de la diferenciación interna del campesinado, respondiendo éste con un mayor acceso a la explotación de la tierra. A partir de este momento tanto propietarios como campesinos tendrán posiciones encontradas como producto de una mayor diferenciación de clase.

Las medidas agrarias liberales han dado a la burguesía la posibilidad de acceder a la titularidad jurídica de la tierra que ya detentaban a través del arrendamiento. Ahora, una vez que los medios de producción están en sus manos, acceden al control del poder político y social para garantizar el mantenimiento y la reproducción de las nuevas relaciones de producción y defenderlas de los posibles ataques de aquellos que han sido desposeídos y que han salido perjudicados del proceso transformador. Así pues, la consolidación del sistema constitucional a mediados del XIX les garantiza y les ofrece la posibilidad de hacerlo.

(12) Si bien es cierto que la oferta de trabajo existente en la Vega y lo coyuntural de esta primera crisis de la remolacha azucarera contribuyó a estabilizar la situación durante estos años. 


\subsection{El Ayuntamiento de Santa Fe y el Blenio Progresista (1854-1856).}

Durante el año de 1856 se suceden en Santa Fe dos corporaciones municipales. La primera, recogida en la tabla IV, producto de la «descentralización. y de la edemocratización.13 -entendida ésta como la ampliación del cuerpo electoral hasta todos los contribuyentes, en su mayoría perceptores de rentas agrarias- que propició la política municipal llevada a cabo durante el denominado :Bienio Progresista.. La segunda, producto del rotundo cambio propiciado por la llegada al poder de la Unión Liberal ${ }^{14}$ eliminando el anterior gobierno municipal, recogida en la tabla V.

A primera vista la corporación del mes de abril del 56 refleja cierto equilibrio y representatividad al aparecer individuos pertenecientes a distintos grupos sociales, diferenciados fundamentalmente por el acceso o no a la propiedad o el arrendamiento de la tierra. Más de la mitad de ellos son grandes propietarios y arrendatarios, situados en la cúspide social de la comunidad, controlando un líquido imponible superior a los 1000 rs. Otros tres de ellos son considerados como medianos propietarios y arrendatarios; y sorprendentemente, figuran otros tres concejales aparentemente desvinculados de la tierra ${ }^{15}$.

Tabla IV

Composición del Ayuntamiento en abril de 1856.

$\begin{array}{llrc}\text { Cargo } & \text { Nombre } & \text { Propiedad - } & \text { Arrendamiento } \\ \text { Alcalde } & \text { José Aranda y Espada } & 7204 & 3015 \\ \text { Concejal } & \text { Fco. Pedro González } & 9188 & 2169 \\ \text { Concejal } & \text { Agustín Rosales } & 4346 & 1273 \\ \text { Concejal } & \text { Agustín González Carrillo } & 3032 & 1829 \\ \text { Concejal } & \text { J. Dios González Aurioles } & 2668 & 585 \\ \text { Concejal } & \text { Cristóbal Pastor Rodríguez } & 1440 & 1661 \\ \text { Concejal } & \text { Antonio Aguilera } & 340 & 80 \\ \text { Concejal } & \text { Fco. Calbo Ruiz } & 160 & 493 \\ \text { Concejal } & \text { Antonio Delgado Camacho } & 0 & 0 \\ \text { Concejal } & \text { Antonio Ruano } & 0 & 0 \\ \text { Concejal } & \text { Isidro Puy } & 0 & 0\end{array}$

Fuente: Actas de Cabildo y Amillaramiento de 1856 (A.M. Santa Fe).

(13) Castro, C. La Revolución Liberal y los municipios españoles (1812-1868). Madrid: A. Editorial, 1979. Pags. 285-289.

(14) Solé Tura, J. y Aja, E. Op. Cit. Pags. 47-50.

(15) Frías Corredor, C. Op. Cit. Pags. 331-333. 
En un primer momento, esta relativa representatividad podríamos atribuirla a los efectos democratizadores ocasionados por los progresis$\operatorname{tas}^{16}$ que impide el control directo y absoluto de los resortes del poder político municipal por parte de la burguesía agraria. Esta visión se ve alterada sustancialmente cuando acudimos a fuentes alternativas ${ }^{17}$ que nos proporcionen si existe alguna relación de vinculación o dependencia de tipo económico y/o extraeconómico entre los concejales no propietarios y la oligarquía agraria local.

En efecto, si sumamos otro elemento de análisis que enriquezca y complejize el entramado de relaciones sociales como es la familia, considerada ésta como el marco preciso de aquéllas en las sociedades campesinas, la composición social del ayuntamiento termina de configurarse. A través de los inventarios post-morten hemos podido reconstruir los lazos familiares que unen a varias de las familias implicadas en los puestos municipales. Así, Juan de Dios Gonzalez Aurioles, mediano propietario y uno de los mayores compradores de bienes nacionales durante la desamortización de Mendizábal ${ }^{18}$ es abuelo paterno de Fco Pedro Gonzalez. En segundo lugar, la derrama general del año 1856 que recoge los líquidos imponibles por actividades, además del rústico, indica que Antonio Delgado Camacho posee 2000 rs de utilidad por una Abacería, Antonio Ruano 600 rs por venta de dulces, e Isidro Puy tiene 1000 rs por panadero. Por tanto no se trata de individuos desposeídos sino de perceptores de líquidos importantes, aunque por conceptos diferentes. En último lugar y utilizando la misma fuente ${ }^{19}$ hemos podido establecer relaciones económicas, de dependencia, entre Antonio Ruano e Isidro Puy y las familias de los Carrillo y los Rosales.

Por tanto, nuestras sospechas se ven confirmadas y la posible democratización aparece mucho más debilitada. Todo el aparato de poder local esta completamente en manos de la burguesía agraria. La forma de control es evidente, no copar todos los cargos por los titulares de la oligarquía, pero si a través de su familia o testaferros que beneficiados por unas relaciones económicas de dependencia entre ellos, representan únicamente los intereses de quienes les deja llegar al poder.

El cambio político suscitado con el golpe militar de O'Donnell provoca la desaparición de los gobiernos municipales anteriores y la constitución de un nuevo gobierno municipal. El acta de cabildo celebrada el 19 de Agosto de 1856 en sesión abierta se dio lectura a una orden del Señor

(16) Artola Gallego, M. Partidos y programas políticos (1808-1936). Madrid: Ariel, 1974.

- Pags. 50-51.

(17) Archivo de Protocolos Notariales de Granada.

(18) Gómez Oliver, M. y Gonzalez de Molina, M. Op. cit.

(19) Archivo de Protocolos Notariales de Granada. 
Gobernador Civil de la Provincia, fechada el 17 del mismo, por la que se deponía a la corporación municipal y se nombraba otra nueva con arreglo a sus facultades extraordinarias que le atribuye el estado especial en que se haya este distrito. La nueva corporación municipal es La siguiente:

Tabla V

Composición del Ayuntamiento en agosto de 1856.

$\begin{array}{llrr}\text { Cargo } & \text { Nombre } & \text { Propiedad - Arrendamiento } \\ {\text { Alcalde } 1^{\varrho}} & \text { Francisco Herrera } & 18912 & 1592 \\ \text { Alcalde }^{\circ} & \text { Diego Carrillo de Albornoz } & 1206 & 0 \\ \text { Concejal } & \text { Fco. Pedro González } & 9188 & 2169 \\ \text { Concejal } & \text { Juan M. González Carrillo } & 9535 & 3989 \\ \text { Concejal } & \text { Antonio Rosales García } & 9282 & 1909 \\ \text { Concejal } & \text { Juan Cabezas García } & 2124 & 533 \\ \text { Concejal } & \text { Cristóbal Rodríguez Pastor } & 1410 & 1661 \\ \text { Concejal } & \text { José Torres Lariño } & 360 & 80 \\ \text { Concejal } & \text { José Ledesma } & 0 & 0 \\ \text { Concejal } & \text { Joaquín Rodríguez } & 0 & 0 \\ \text { Concejal } & \text { Antonio Arroyo } & 0 & 0\end{array}$

Fuente: Actas de Cabildo y Amillaramiento de 1856 (A.M. Santa Fe).

El cambio político en la nación tiene una repercus: ón inmediata en la composición de los miembros del ayuntamiento. El primer rasgo a destacar es el reforzamiento del peso de las rentas obtenidas de la tierra dentro de la corporación municipal. El producto líquido por propiedad que sopesaba la anterior corporación ascendía a 28378; ahora es de 52017. El obtenido por arrendamiento sufre solo una pequeña subida, pasando de 11105 a 11933. La presencia de las mismas familias es evidente, casi todas grandes propietarios y arrendatarios, exponentes claros de la burguesía agraria beneficiada de las reformas liberales, cuyo grado de cohesión en la articulación del control del poder municipal se ve reforzado.

La nueva corporación municipal tiene tres componentes que no poseen tierra en propiedad y un propietario que no es arrendatario. De nuevo las fuentes alternativas nos permiten definir de forma más correcta el entramado de intereses de la corporación municipal. Diego Carrillo de Albornoz, considerado como mediano propietario, pertenece a una de las familias de mayores rentas agrarias, además es abogado. José Ledesma tiene 600 rs en concepto de urbana y 4000 rs que le rinde su profesión de médico cirujano con dotación en varios pueblos de la vega. José Torres Lariño es capataz y por tanto asociado de manera directa a los intereses de los grandes propietarios. Joaquín Rodríguez es albañil pero su herma- 
na Rosa Rodríguez y su hermano José Rodríguez suman más de 5000 rs líquidos en concepto de Rústica. De esta forma propietarios y profesiones liberales dominan todo el aparato local.

Como decíamos, ahora la tarea de la burguesía pasa por la defensa de sus intereses y de la situación de privilegio en la que han quedado tras las reformas burguesas, mucho más en situaciones de crisis política y social como la del 56.

Una de las atribuciones de los concejales y del alcalde es el nombramiento de la junta pericial. Este organismo tiene una especial importancia puesto que es quien va confeccionar los amillaramientos y las cuotas impositivas, base del repartimiento. Ni que decir tiene que es aquí donde la oligarquía agraria va a obtener buena parte de sus beneficios políticos en forma de prestaciones económicas. Únicamente se van a producir protestas cuando la distribución de las cuotas afectan a muchos contribuyentes y de manera casi provocadora. Tenemos un ejemplo de ello. En la acta de cabildo de 22 de agosto de 1856, cuatro días después de la formación del nuevo ayuntamiento, se forma la nueva junta pericial y se leen más de 25 escritos reclamando una baja en la derrama. Esta situación se resuelve aceptando los escritos que piden una baja en el líquido y la subida sistemática de más de 3500 rs fundamentalmente entre los mayores contribuyentes: 1000 rs a Fco Herrera (alcalde), 1200 rs a Francisco Rosales Blanca, 700 a Diego Magia Herrera, 180 rs a Agustín Rosales, 150 a Manuel Rosales, 240 a Miguel Henriquez, 240 a Antonio Diez de Rivera (mayor contribuyente), etc y una lista mayor donde están todos los nombres de los mayores contribuyentes.

Parece pues que las clases más bajas quedan ciertamente desamparadas políticamente y sin mecanismos de representación que puedan defender sus intereses en los ayuntamientos. Ante esta situación, en momentos de crisis coyuntural, como malas cosechas, inundaciones del Genil, plagas, etc... los campesinos más pobres, es decir la mayoría de ellos, contestan enfrentándose al los poderes establecidos por el estado nación. La forma de lucha o de resistencia campesina. pasa, en primer lugar, por la negativa a pagar los impuestos, síntoma de protesta ante el proceso de dominación política y económica que sufren. También tenemos un ejemplo de ello. Reunida la corporación municipal el 12 de diciembre del 56, junto a los mayores contribuyentes, se presentan los expedientes instruidos por el ejecutor de apremios dando a conocer una lista de contribuyentes y los motivos que han hecho imposible el cobro de los impuestos. En total son 120, todos ellos vecinos, y el motivo generalizado de no pagar la contribución es: "por hallarse en la mayor miseria y sin bienes ni efectos que puedan venderse por tan pequeña cantidad. Hemos identificado a 50 de ellos como arrendatarios en el 
Amillaramiento de 1856 , el resto podrían ser pequeños subarrendamientos, que no figuran en dicha fuente. Esta es una de las alternativas de resistencia que adoptan las clases menos favorecidas por los cambios y el desarrollo de unas relaciones de producción capitalistas en momentos de crisis. Su exclusión del control de poder municipal hace que no dispongan de mecanismos políticos efectivos tendentes a una regulación más proporcional de los impuestos y de la riqueza de la comunidad y no puedan controlar situaciones abusivas como las descritas.

\subsection{El sistema político de la Restauración y el poder local en Santa Fe.}

Como hemos descrito anteriormente el sistema político de la Restauración garantizó plenamente la consolidación, como grupo social hegemónico, de la burguesía agraria andaluza surgida a través de las medidas legislativas generadas a lo largo de todo el siglo y generó por medio de un absoluto control de las principales instituciones políticas públicas el mantenimiento de las condiciones posibilitadoras de su reproducción y expansión, aún a costa de originar unas relaciones socioeconómicas caracterizadas por las desigualdades y los desequilibrios; y de marginar sistemáticamente a las clases populares de una verdadera articulación de sus intereses en los principales mecanismos de representación y control político.

Tabla VI.

Composición del Ayuntamiento en 1887.

$\begin{array}{llcrc}\text { Cargo } & \text { Nombre } & \text { Propiedad - } & \text { Arrendamiento } & \text { No Contri. } \\ \text { Alcalde } & \text { Antonio Rosales González } & 2688 & 108 & 17 \\ \text { Concejal } & \text { Eusebio Carrillo Herrera } & 7039 & 0 & 5 \\ \text { Concejal } & \text { Aureliano Rosales Rosales } & 3350 & 5 & 12 \\ \text { Concejal } & \text { Silverio Carrillo Herrera } & 2915 & 807 & 13 \\ \text { Concejal } & \text { Natalio Herrera Rosales } & 2660 & 332 & 14 \\ \text { Concejal } & \text { Agustín Pacheco Rosales } & 1829 & 863 & 18 \\ \text { Concejal } & \text { Agustín Rosales García } & 2178 & 0 & 21 \\ \text { Concejal } & \text { J. Dios González Blanca } & 1417 & 19 & 29 \\ \text { Concejal } & \text { Estanis. Nogueras González } & 1169 & 55 & 33 \\ \text { Concejal } & \text { Daniel Agrela García } & 424 & 561 & 41 \\ \text { Concejal } & \text { Francisco Calbo Ruiz } & 176 & 510 & 59 \\ \text { Concejal } & \text { Eduardo Carrillo Herrera } & 570 & 0 & 71 \\ \text { Concejal } & \text { Miguel Ortega González } & 360 & 178 & 75 \\ \text { Alcalde } & \text { Eduardo Páez Vargas } & 0 & 526 & 77 \\ \text { Concejal } & \text { Juan García Carrillo } & 409 & 87 & 80 \\ \text { Concejal } & \text { Francisco García Jiménez } & 291 & 95 & 94 \\ \text { Concejal } & \text { Antonio Pérez Quesada } & 148 & 236 & 96 \\ \text { Concejal } & \text { Antonio Nieves Velázquez } & 315 & 0 & 115 \\ \text { Concejal } & \text { Francisco García Cardona } & 12 & 0 & 192\end{array}$

Fuente: Actas de Cabildo y Repartimiento de la Contribución Territorial y Pecuaria para el año económico de 1887-88 (A.M. Santa Fe). 
En este sentido, el papel desempeñado por los Ayuntamientos viene a ser esencial, sobre todo, si consideramos la necesidad de consolidar definitivamente la propiedad privada "pura. de los medios de producción, hecho éste especialmente difícil a tenor de la secular tradición de aprovechamientos de bienes, usos y costumbres comunales en el campo andaluz. La función llevada a cabo por los ayuntamientos de control de los conflictos de clases originados por unas relaciones sociales de producción capitalistas especialmente crudas en el campo andaluz, de defensa permanente del dominio por parte de las oligarquías agrarias locales de los resortes del poder y la manipulación de los organismos municipales, le confiere una significación muy relevante ${ }^{20}$.

Efectivamente, el control del ayuntamiento santafesino ${ }^{21}$ por parte de la burguesía agraria local es incuestionable. Del total de 19 concejales elegidos en dos comicios 9 pertenecen, con un líquido imponible por rústica y colonia que supera con creces las mil pesetas, a la oligarquía constituida por los grandes propietarios agrarios (ver tabla II), como manifiesta el número de orden que ocupan en la lista de contribuyentes de Santa Fé. Otros 9 ediles mantienen un líquido imponible en concepto de rústica y colonia que los sitúa, por el valor de una y otra, como medianos propietarios y arrendatarios ${ }^{22}$. Por último, sorprende a primera vista el particular caso de Francisco Garcia Cardona con 12 pesetas de líquido imponible en concepto de rústica; sin embargo, las 153 pesetas de líquido imponible por propiedad urbana manifestadas en el Repartimiento de 1887-88 y el hecho de ser miembro de una de las familias con mayor prestigio económico y social durante la primera mitad del XIX, despeja las incógnitas que originariamente surgían.

Este manifiesto y férreo control de la oligarquía agraria del poder político local se acentúa si introducimos el concepto de "unidad familiar* comprendido como verdadero sujeto de las relaciones socioeconómicas en el campo decimonónico andaluz $z^{23}$. El cúmulo de estrechas relaciones de parentesco entre los miembros del ayuntamiento -y de los dos señala-

(20) Castro, C. Op. Cit. Ya hemos mostrado anteriormente algunas de las atribuciones de los ayuntamientos.

(21) Boletín Oficial de la Provincia de Granada, núm.82, 14-IV-1887 y El Defensor de Granada, núm.2543, 1-VII-1887. El número de concejales reseñados excede los 12 componentes estipulados; esto se debe a que hemos incluido a todos los ediles de los dos gobiernos municipales que separa las elecciones para renovarlos la primavera de 1887.

(22) Además, uno de ellos sobresale con un líquido imponible valorado en 986 pesetas equitativamente distribuido entre rústica y colonia- que lo acerca más al grupo de grandes propietarios que al de medianos. Por otra parte, la importancia del arrendamiento en su forma de acceso a la explotación de la tierra manifiesta unas estrechas relaciones con el sector de los grandes propietarios.

(23) Heran Haen, F. Tierra y parentesco en el campo sevillano: la revolución agricola del siglo XIX. Madrid: Servicio de publicaciones agrarias, 1980. Pags. 10-17. Hace ya 
dos en 1856- perfilan aún más el control de esta oligarquía agraria que, mediante prácticas endogámicas de producción, mantenimiento, reproducción y expansión de sus bases materiales de hegemonía, muestra ya una concepción patrimonial del poder político local copado siempre por diferentes miembros de las familias "que comparten y se reparten el dominio de la tierra y, en definitiva, de la vida de esta comunidad ${ }^{24}$. Si el sistema electoral, basado en el sufragio censitario impuesto por la ley de $1877^{25}$, facilitaba -dadas las características de la distribución de la propiedad de la tierra- el control de los procesos electorales y, por ende, el dominio del poder local, el sistema político y la legislación emanada de sus principios terminaba de cerrar unos ámbitos de poder limitados a un reducidísimo número de efamilias. donde la escasa representatividad del sistema se pervierte asiduamente. Este es el caso de la aparición y mantenimiento como concejales interinos de cuatro individuos no sometidos al proceso electoral ${ }^{26}$, que por haber ocupado un sillón municipal en el pasado, adquieren este derecho al quedar vacantes cuatro de los doce miembros del gobierno ${ }^{27}$. En definitiva, permanencia de las mismas :familias* que constituyen la oligarquía agraria en el poder local de Santa Fé, sin que las diferentes coyunturas políticas la cuestionara sustancialmente.

\section{EL SUFRAGIO UNIVERSAL Y EL PODER POLITICO}

Con el ascenso del Partido Liberal al poder en 1885 se desarrolló un aparato legislativo -donde destacaban esencialmente la ley de sufragio universal de 1890 y la ley de Asociaciones 1887-valorado como progresista

tiempo este autor manifestó la importancia de la familia. en el estudio de la evolución de la burguesía agraria andaluza.

(24) Archivo de Protocolos Notariales de Granada. No es este el lugar de extendernos en el tratamiento de las familias., pero la muestra del árbol genealógico de la familia de los Rosales expuesto y los siguientes casos ilustran sobradamente lo expresado. Si espectacular es el caso de los ROSALES, no lo es menos el de los tres hermanos CARRILLO emparentados, a través del matrimonio de Eduardo Carrillo con Leocadia Nogueras Gonzalez, con Estanislao Nogueras Gonzalez.

(25) Artola Gallego, M. Op. Cit. Pags. 53-56.

(26) Actas de Cabildo del año 1887-88. Los ya conocidos Agustín Rosales Garcia y Francisco Calvo Ruiz -concejales en 1856-, junto con Antonio Nieves Velazquez y Antonio Perez Quesada acceden al ayuntamiento, en calidad de concejales interinos, manteniéndose durante dos años.

(27) Actas de Cabildo del año 1887 y 1888. Los concejales Daniel Agrela Garcia, Eduardo Carrillo Herrera y Eusebio Carrillo Herrera se ven invalucrados en un proceso judicial, impulsado por el Juez Especial de Instrucción de Granada, por defraudación a la Hacienda y por malversación y falsedad de caudales públicos, se ven obligados a abandonar sus cargos municipales. El concejal Estanislao Nogueras Gonzalez renuncia a su cargo al optar por el puesto de Juez Municipal de Santa Fé. Este cargo, de fundamental importancia en el mantenimiento del orden social y en la proyección de la estrategia de poder de la clase dominante, cierra el circuito de poder político local santafesino. 
en cuanto suponía, o al menos lo parecía, un aumento notable del cuerpo electoral mediante la ampliación del voto a toda la población masculina mayor de 25 años y una conquista fundamental para el trabajador.

Un repaso a las oscilaciones de la extensión del cuerpo electoral durante el siglo XIX evidencia que los aparatos y las instituciones del Estado español contemporáneo habían sido forjados históricamente bajo la única y excluyente orientación de una ínfima minoría ${ }^{28}$. Desde esta perspectiva la ley de sufragio universal masculino para mayores de 25 años, implantada por el gobierno liberal de Sagasta, arroja una ampliación del cuerpo electoral espectacular, llegándose a un 27 por ciento de la población.

Tabla VII.

Composición del Ayuntamiento en 1891.

$\begin{array}{llcc}\text { Cargo } & \text { Nombre } & \text { Propiedad + Arrendamiento } & \mathrm{N}^{N} \text { Contri. } \\ \text { Alcalde } & \text { Natalio Herrera Rosales } & 3084 & 12 \\ \text { Concejal } & \text { Aureliano Rosales Rosales } & 3302 & 11 \\ \text { Concejal } & \text { Agustín Rosales García } & 2122 & 13 \\ \text { Concejal } & \text { Agustín Pacheco Rosales } & 2601 & 14 \\ \text { Concejal } & \text { Antonio Rosales González } & 2147 & 20 \\ \text { Concejal } & \text { Eduardo Páez Vargas } & 1980 & 23 \\ \text { Concejal } & \text { J. Dios González Blanca } & 1436 & 30 \\ \text { Concejal } & \text { Enrique Carrillo González } & 1250 & 38 \\ \text { Concejal } & \text { Francisco García Jiménez } & 480 & 98 \\ \text { Concejal } & \text { Eduardo Carrillo Herrera } & 398 & 120 \\ \text { Concejal } & \text { Daniel Agrela García } & 397 & 119 \\ \text { Concejal } & \text { Antonio Nieves Velázquez } & 315 & 126\end{array}$

Fuente: Actas de Cabildo del año 1891 y Repartimiento de la Contribución Territorial y Pecuaria de 1893-94 (A.M. Santa Fe).

Leyenda: En las corporaciones municipales de 1891 y 1893 los concejales figuran con el líquido imponible resultante de la suma de rústica y colonia a causa de que el Repartimiento de la Contribución para el año 1892-93 no recoge separadamente los conceptos mencionados.

Sin embargo, este incremento de la participación popular en el sistema político español parece diluirse completamente si consideramos la presión ejercida por unas determinadas relaciones de producción -ya ex-

(28) Un estudio de estas oscilaciones fue desarrollado por Eliseo AJA Y Jordi SOLE TURA, op. cit., Pags. 122-125. 
puestas en apartados anteriores- en el campo Alto Andaluz, generadoras de unos mecanismos de control social y político que distorsionaban cualquier intento de ademocratización. puramente formal, y si consideramos las propias limitaciones del decreto de 5 de nowiembre de 1890 que no había modificado las condiciones de elegibilidad establecidas en $1877^{29}$ o que -garantizaba. la formación del censo electoral a través de las Juntas Central, Provincial y Municipal del Censo electoral cuya composición estaba reservada estrictamente a los miembros, en palabras de Miguel Artola del eestablishment político-administrativo.30. Esto es al menos lo que parece deducirse de un examen de la realidad del poder político local tras la implantación del sufragio universal masculino en el caso que nos ocupa ${ }^{31}$.

En ambas corporaciones municipales, con un total de 11 concejales cada una de ellas, más de la mitad de sus integrantes -8 en 1891 y 6 en 1893-forman parte del grupo social que controla la tierra, fundamentalmente a través de su propieda $\mathrm{d}^{32}$; mientras que el resto de los ediles, en las dos fechas mencionadas, forman parte de lo que podemos denominar medianos propietarios o arrendatarios, siendo éste el primer caso en que no figura nombre alguno con líquido imponible inferior a las 250 pesetas. La evidencia de la permanencia en los órganos de poder local de la minoría que posee el dominio de la tierra (ver tabla III) y que dominaba, desde al menos 50 años antes, los órganos de control político local, es incuestionable, sin que sea patente efecto alguno como consecuencia de la puesta en práctica de la nueva legislación.

Si en el discurso de nuestro análisis reintroducimos el concepto de * unidad familiar" como sujeto en torno al cual se configura el conjunto de

(29) Artola Gallego, M. Op. cit. Pags. 59-60.

(30) Ibidem. Pags. 59-60. La legislación preveía que la Junta Municipal debía estar integrada por los individuos del ayuntamiento y los ex-alcaldes, con lo que su labor garantizadora. quedaba fuera de toda duda.

Boletín Oficial de la Provincia de Granada, núm. 90, 20-IV-1892. En lo que respecta a la composición de la Junta Provincial de Granada -citada a continuación-, formada por miembros de la Diputación provincial según lo estipulado, destacan relevantes miembros de la élite económico-política santafesina, poniéndose de manifiesto el peso específico de la burguesía agraria de Santa Fé en el conjunto de los organismos de poder provincial y evidencian el grado de control del sistema político local existente.

Varios son los vecinos de Santa Fé componentes de la Junta Provincial del Censo Electoral de 1892: Francisco Herrera aparece en concepto de ex-presidente del citado organismo; Rafael Rada Marín figura en concepto de ex-vicepresidente del mismo; Francisco Castro Almendros como diputado provincial elegido mayor número de veces; Segismundo Rosales Rosales también como diputado provincial.

(31) Con la comparación entrambas corporaciones municipales pretendemos rastrear el grado de ampliación real de intereses en la articulación del poder local.

(32) En este análisis, como en los años anteriores, seguimos la clasificación propuesta por Carmen Frías Corredor, Op. Cit. Pags. 331-333. 
la vida santafesina nuestras observaciones quedan notablemente enriquecidas. A primera vista detectamos como unos cuantos apellidos se repiten machaconamente en los cargos municipales: HERRERA, CARRILLO, ROSALES, GONZALEZ, PACHECO; si observamos más detenidamente colegimos una idea casi patrimonial del poder local donde padres e hijos, hermanos y cuñados lo comparten y lo reparten atendiendo a su privilegiado estatus socioeconómico ${ }^{33}$; finalmente, si recurrimos al esbozado árbol genealógico de los ROSALES terminamos de comprender la composición de los diferentes ayuntamientos.

Tabla VIII

Composición del Ayuntamiento en 1893.

$\begin{array}{llcc}\text { Cargo } & \text { Nombre } & \text { Propiedad + Arrendamiento } & \text { No Contri. } \\ \text { Alcalde } & \text { Antonio Rosales González } & 2147 & 20 \\ \text { Concejal } & \text { Aureliano Rosales Rosales } & 3002 & 11 \\ \text { Concejal } & \text { Agustín Pacheco Rosales } & 2601 & 14 \\ \text { Concejal } & \text { J. Dios González Blanca } & 1436 & 30 \\ \text { Concejal } & \text { Enrique Carrillo González } & 1250 & 38 \\ \text { Concejal } & \text { Eduardo González Carrillo } & 1029 & 47 \\ \text { Concejal } & \text { Juan García Carrillo } & 502 & 80 \\ \text { Concejal } & \text { Gabriel Roldán Alvarez } & 490 & 84 \\ \text { Concejal } & \text { Manuel Bal. Nieves Velázquez } & 347 & 115 \\ \text { Concejal } & \text { Antonio Arenas Granados } & 335 & 118 \\ \text { Concejal } & \text { Antonio Nieves Velázquez } & 315 & 126\end{array}$

Fuentes: Actas de Cabildo de 1893 y Repartimiento de la Riqueza Territorial y Pecuaria para el año 1892-93 (A.M. Santa Fe)

La incidencia en el caso de Santa Fé de la instauración, por parte del poder político central, del sufragio universal masculino no tuvo ninguna repercusión sobre los resultados electorales de una comunidad, ajena en la mayor parte de sus miembros a la lógica del sistema político liberal, donde se impone el poder patrimonial y hegemónico de una oligarquía socioeconómica cuya fuerza emana de las relaciones de dependencia y subordinación establecidas respecto al conjunto de la comunidad en base a su control de la propiedad y de la explotación de la tierra.

(33) Archivo de Protocolos Notariales de Granada. Natalio Herrera Rosales, concejal tanto en 1887 como en 1891, es hijo de Francisco Herrera, alcalde y concejal en los dos gobiernos municipales de 1856. Asimismo, la perseverancia de Juan de Dios Gonzalez Blanca en el poder local, concejal en 1887, 1891 y 1892, es digna de todo elogio, sobre todo si tenemos en cuenta que tuvo que recoger el testigo, junto a su primo, Fco Pedro Gonzalez, de su abuelo, Juan de Dios Gonzalez Aurioles, también muy sinteresado- por la política alocal. Los Nieves Velazquez -Antonio es concejal en 1887, 1891 y 1892, y Manuel Baltasar lo es en 1893- muestran otro ejemplo de reparto de poder político como thermanos. y entre hermanos. 
Finalmente, si analizamos la composición del aparato de justicia municipal ${ }^{34}$-pieza clave en el desarrollo y mantenimiento de las estrategias de poder de la clase dominante ${ }^{35}$ - formado por el conocido exconcejal y ex-juez municipal Estanislao Nogueras Gonzalez como Juez Municipal nombrado por el gobernador civil de la provincia y, por Francisco Vazquez Rosales como fiscal municipal -emparentado en segundo grado con los Rosales- se configura totalmente la organización del poder local, cuestionándose la dirección 'descendente* de éste en Santa $\mathrm{Fé}^{36}$.

En definitiva, un absoluto control del poder local, por parte de una oligarquía económica constituida sobre el dominio de la mayor parte de la tierra (ver tabla III), que permanece incólume ante tentativas de cambio como la constituida por la introducción del sufragio electoral masculino en 1890. Las relaciones sociales de dependencia y subordinación generadas entre una élite económica y el resto de la sociedad santafesina, fundamentadas en la formación y consolidación de una distribución de la propiedad y explotación de la tierra determinada a lo largo de todo el siglo $\mathrm{XIX}^{37}$-donde el trabajo asalariado es fundamental para la reproducción de un número importante de familias y donde el acceso a la tierra por medio del arrendamiento de pequeñas propiedades constituye igualmente la forma de manteniendo de un grupo también significativo de pequeños campesinos ${ }^{38}$-, posibilitan un férreo control del entramado social y político ${ }^{39}$ de la sociedad que se veía favorecido por el sistema político de la Restauración.

\section{CONCLUSIONES}

La progresiva penetración de las relaciones de producción capitalistas durante el siglo XIX facilitó la consolidación de una potente burguesía agraria cuyo poder político, basado en las rèlaciones de dependencia

(34) Boletín Oficial de la Provincia de Granada, núm.10. 12-I-1892.

(35) Cruz Artacho, S. LLa Administración de la Justicia en Granada durante el primer tercio del siglo XX. La acción de los jueces municipales. En Espacio, Tiempo y Forma, Serie V, $\mathrm{H}^{\mathrm{Q}}$ Contemporánea, t.3, 1990, Pags. 173-189.

(36) Cruz Artacho, S., Martínez López, D., Martínez Martín, M. ‘Procesos electorales y mecanismos de control político: la composición social del cuerpo electoral granadino tras la promulgación del Sufragio Universal masculino. Comunicación presentada al Congreso sobre Caciquismo y República en Andalucia(1891-1936), en Puerto de Santa Magia(Cádiz) 25-27 de septiembre de 1991, Pags. 3-4.

(37) Martínez Martín, M. y Gonzalez de Molina, M. Notas sobre propiedad y explotación como variables explicativas en la historia de las comunidades campesinas andaluzas. Trabajo presentado en el Seminario de Historia Agraria, celebrado en Menorca en Septiembre de 1990.

(38) Martínez Martín, M. Op. Cit.

(39) Scott, J. Op. Cit. Pags. 63-77. 
establecidas por el propio modelo socioeconómico generado sobre el control que ésta ejerce sobre el principal factor de producción, se mantiene incólume a lo largo de la segunda mitad del XIX.

Antes de 1891 la permanencia del sufragio censitario garantizaba de manera institucional el acceso al poder de las clases dominantes, marginando al conjunto de la sociedad santafesina. La introducción del sufragio universal en nada va a alterar la distribución y control del poder local. Pensamos que dicha burguesía mantiene el poder político ahora por mecanismos electorales que proporcionan un mayor número de votos. Se ha cambiado la forma jurídica que limitaba el acceso al voto por los mecanismos de coacción derivados de un mayor control del poder económico. Ahora los titulares del poder local en Santa Fe poseen la legitimidad formal de la mayoría de la población. Este correlato entre poder económico y control político viene a reforzar la hipótesis aascendente. a la hora de explicar la articulación de las redes de dependencia política ${ }^{40}$.

(40) Esta visión queda suficientemente explicada en el trabajo que presentamos sobre .Procesos electorales y mecanismos.... Op. Cit. Pags. 3-4. 